\title{
1. Introduction to sports and society: scholarship, activism and impact
}

Elizabeth C.J. Pike

\section{INTRODUCTION}

The Research Handbook on Sports and Society provides challenging, critical examinations of the complex issues that surround sports in contemporary societies. Contributors to the Handbook are world-leading scholars in the area of sports and society who were invited to weave together their personal research journeys with significant social issues and controversies in sport. In so doing, the authors reflect on what motivated them to do their research, outline their theoretical framework and methodological approach, examine the current state of knowledge regarding their specific area of expertise, consider what have been the main outcomes or impact of their research (including what have been the constraints on research impact), and offer recommendations for future policy and practice. The Handbook is organised around the key themes of the Governance, the Economics, Events, the Workplace, the Athletes, the Issues and the Future. It is worthy of note that the Handbook was commissioned prior to the global coronavirus pandemic, but most chapters were finalised in 2020 during the pandemic. Furthermore, during this time period, the Black Lives Matter movement gained global attention, and included activities and protests related to sports events and supported by high-profile athletes, following the death of African American George Floyd while he was restrained by a white police officer. Many of the contributors therefore choose to reflect on the ways in which the pandemic and the Black Lives Matters movement exposed social issues and fragilities, and the ways that these were played out in sporting arenas, whether physically or virtually.

My personal trajectory to becoming a sociology of sport scholar is perhaps unusual as I did not set out on my studies with the intention to be a sociologist or with any particular aptitude for sport. I was the first person in my family to go to university, with the full support of my parents who had left school aged 14, but despite the expressed reservations of teachers at my secondary school (an all-female school where I was very happy but which focused on teaching girls the domestic science and secretarial skills which appeared to be the extent of the school's ambition for most of its graduates). I was offered a place at Canterbury Christ Church College, with the intention of reading history and becoming a journalist. The degrees were joint honours and I took as my minor subject 'Movement Studies', reflecting a general enthusiasm for physical activity albeit never achieving any particular competitive standard. The Head of the Department of Movement Studies was Bob Pearton. Bob was an inspirational lecturer who challenged me to think critically about the significance of sport in society and, in particular, introduced me to the work of Erving Goffman which became the focus of one of two undergraduate dissertations that I produced under Bob's supervision. I changed my minor subject to become my major to enable me to study more of the sociology of sport and, with Bob's encouragement, secured a place at Loughborough University to read for a Masters' 


\section{Research handbook on sports and society}

degree. Poignantly, Bob passed away while I was writing this chapter. At Loughborough, I continued my learning of the sociology of sport and related methodologies, and here Andrew Sparkes introduced me to new ways of 'doing' sociology. In particular, Andrew encouraged his students to challenge uncritical acceptance of the positivist paradigm that dominated the study of sport at that time, and to engage with the interpretivist paradigm and qualitative research methods. This informed my own thesis, in which I reflected on the challenges that I encountered when attempting to infiltrate a close-knit community of women rugby players to understand their engagement with violent behaviour, with apparent acceptance, and even reinforcement of, misogynistic attitudes. My naïve attempt to immerse myself in their culture, and their understandable resistance, taught me an enormous amount about the 'messiness' of research methodologies, the necessary balance between involvement and detachment, and to respect research participants.

As a sociology of sport student, I was particularly struck by the widespread discourse that sporting activities in their various manifestations are inherently healthy (both physically and morally), and have the capacity to prevent deviant behaviour and build positively valued characteristics (see Pike, 2014), something that Jay Coakley calls The Great Sport Myth as he explains in Chapter 27. Research informs us that, even when athletes and spectators may be temporarily distracted by sport and learn positive social behaviours, this does not always influence how they behave in other areas of their life, and that it is possible that sports may be morally neutral, or even provide a context and environment for deviancy and negative social values (Coakley and Pike, 2014). My early research was primarily ethnographic in approach, and informed by the work of Goffman to understand such behaviours.

As I developed my understanding of these issues and social processes, I turned my sociological imagination to the injurious risk-taking behaviours of many athletes - a trend that is widespread and challenges the perception of sport as inherently healthy. This topic became the focus of my doctoral thesis in which I examined the risk, pain and injury experiences of female rowers through an extensive period of ethnographic research (see Pike, 2000). My PhD supervisor was Joseph Maguire who challenged my framing of the issues within a critical interactionist perspective and broadened my theoretical thinking.

As I have explained elsewhere (Pike, 2014), the study of injury risk became an investigation into 'damaged bodies' in sport more widely. In particular, I came to understand that while injury in sport is generally avoidable, and most injuries are treatable and reversible, some sporting bodies can be damaged in ways that are unavoidable and irreversible. This led me to attempt to better understand the ageing sporting body, given that the ageing process is one that cannot be avoided or reversed. Latterly, my research has focused on the physical activity experiences of older adults, including those living with dementia (see, for example, Bangsbo et al., 2019; Pike, 2019).

Throughout my career, I have given particular attention to the experiences of those who identify as female. During the global coronavirus pandemic, the ageing population and females emerged as two of the social groups most affected by new or exacerbated forms of inequality in sport participation. For example, the focus on the heightened risk of mortality to specific groups such as older adults led some policymakers to construct their management of the virus as action to protect these groups by reducing their access and socialisation with other, less risky groups (in particular, the young and ostensibly healthy). The consequence of this was that many older adults experienced increased and disproportionate constraints on opportunities to engage in physical activities (see Evans et al., 2020). In addition, evidence indicates 
that the pandemic exacerbated the already lower levels of physical activity among women and girls (see Donnelly et al., 2020). These issues are examined throughout this Handbook.

\section{SCHOLARSHIP AND ACTIVISM}

Following a period working at St Mary's College where I was supported to complete my $\mathrm{PhD}$, I moved to the University of Chichester where I met Anita White who became a friend, a critical friend and a mentor. Anita developed my appreciation of the value of sociological scholarship to inform activism. Anita was the inspiration for the Women and Sport Conference that took place in 1994 which led to the Brighton Declaration on Women and Sport, and the formation of the International Working Group on Women and Sport. Anita and I shared ideas and understanding, particularly related to the social structures and processes that enable and constrain women's involvement in sport, and together we established the Anita White Foundation (AWF). The AWF champions gender equity in sport leadership by drawing on impactful research in order to empower female leaders and scholars (www.anitawhitefoundation.co.uk). My work in this area combines interactionist with feminist theories to develop a more critical interactionism (Coakley and Pike, 2014), particularly to inform understanding of the gendered practices in sports leadership and governance (Piggott and Pike, 2019). The impact of this research-informed approach was the development of the Women's Sport Leadership Academy in partnership with Females Achieving Brilliance, which has been delivered across multiple countries and continents, provided the foundations of a global women's leadership network, and informs the continued relationship between scholarship and activism to develop improved opportunities and support for women leaders in sport (see Pike et al., 2018).

It was this kind of work, which focuses on the impact of research on policy and practice, that framed my thinking about the structure and content of the Research Handbook on Sports and Society when I was approached by Edward Elgar to undertake this project.

\section{THE RESEARCH HANDBOOK ON SPORTS AND SOCIETY}

Following the approach from Edward Elgar, I contacted scholars from around the world who I knew to be global leaders on the key topics that form the basis of this book. I identified six key themes which I felt would enable exploration of sports and society from multiple perspectives to provide a holistic understanding. I was also keen that the contributors told the story of their own work and reach in order to develop understanding of this relationship between scholarship and activism which became so central to my own work. Each of the contributors was invited to outline their research journey, theoretical and methodological frameworks, key social issues and controversies, impact and recommendations from their work.

The first part of the book focuses on sports governance. David Hassan of Ulster University introduces the reader to the role of the public intellectual, specifically in the context of the well-established relationship between sport and politics, and the politics of sport governance. Hassan illustrates his research themes with examples of his own work as an active participant and academic researcher in Northern Ireland, and he challenges the reader to consider the impact of their work. In the following chapter, Jorid Hovden reflects on her extensive research journey dealing with politics and gender policies in sport organisations. Her work considers 
gender as a political category, gendered power relationships and gender political strategies characterising the decision-making of sport organisations, illustrated by her work primarily in Norway, and makes a case for the need for intersectional perspectives and ethnographic studies of decision-making processes. Andy Smith then focuses on sports governance at the level of community sport and health, and critically examines the changing landscape of higher education within which academics are increasingly constrained. He identifies some of the professional and moral rationales which underpin the engagement of sociologists of sport in knowledge development and its dissemination to our publics. Finally in this part, Simon Darnell, Sabrina Razack and Janelle Joseph are three Canadian colleagues who draw on their collective understanding of the intersections and divergences of the sociology of sport in relation to social movements, change and activism. In particular, they raise questions, many of which are still to be answered by critical scholars, about the role of digital media in relation to dominance and normativity, including white supremacy.

The second part of the Handbook focuses on the economics of sports. Wladimir Andreff and Nicolas Scelles consider the economic determinants of sport performance. They draw on their extensive research in this field, explaining their methodological approach to identify the value added by sports economics and some recommendations for competition management and forecasting. The next chapter considers the rise of sports betting since the advent of internet gambling. Hibai Lopez-Gonzalez argues that this is a manifestation of modern sport's essential search for quantification and rationality, and presents sports betting as a complex dual phenomenon which is simultaneously a blooming industry and a controversial commodity with issues of integrity and risk behaviours. Andrew Grainger's chapter is grounded in a discussion regarding how the critical analysis of sport, advertising and promotional culture provides important insights into the production and circulation of culture and cultural meaning and the production and reproduction of ideology. This is followed by Lawrence Wenner's interrogation of his extensive research journey and the trajectory of study on media, sports and society. Wenner makes a case for the necessity of interdisciplinarity in the socio-cultural study of mediated sport, and reveals tensions and opportunities in considering the complementary and offset priorities of three distinct scholarly dispositions to studying the communication of sport and sitting debates over studying new media impacts.

The third part of the Handbook contains two chapters that both focus on sporting events, from two related but different perspectives. John Horne discusses research on sports mega-events (SMEs) that he has conducted for more than 30 years. He outlines issues which include defining sports mega-events; the mediation of sports mega-events; their role in urban development processes; the politics of SMEs; legacies and impacts; and resistance to sports mega-events. Yuhei Inoue examines the contribution of sport fandom to the quality of an individual's life, or well-being. In reflecting on his own research in this field, he discusses the possible ways in which the potential of fandom can be leveraged by policymakers and sport practitioners to promote the quality of individual and collective lives.

The fourth part of the Handbook examines a range of issues for those employed within sporting workplaces. Lucy Piggott's work explores key social issues that influence social inequity in and through sport leadership and discusses why it is important for the sector to embrace inclusivity, diversity and equity. In particular, she provides suggestions for how to resist or transform male-dominated structures and cultures to make sports leadership more gender-equitable. The issue of gender equity is picked up by Leanne Norman who considers the global, age-old issue of the underrepresentation of women in coaching workforces. Norman argues that, to 
have long-lasting change, there is a need to approach this issue not just through a 'diversity and inclusion' angle, but also by adopting a social justice lens that focuses on equity, action and systemic change. Jamie Cleland's chapter examines an often under-examined group in sport, the referees, and considers the main sociological reasons behind the significant decrease in the retention of referees in some sports. In particular, Cleland investigates the verbal and physical abuse received by many referees as well as the need for greater support mechanisms and more consistently applied punishments for any offending individual or club. The final chapter in this part is Megan Chawansky's reflections on her personal experiences of volunteerism, particularly in the sport for development and peace (SDP) sector, to highlight definitional challenges with volunteerism. Chawansky's chapter suggests that future research consider explorations of volunteerism through the lens of gender and the method of intersectionality, in order to better conceptualise the difference between local and transnational volunteers.

The Handbook then moves from consideration of the 'workers' to the 'athletes' themselves in the fifth part. Outi Aarresola, Jari Lämsä and Astrid Schubring consider the ways in which the lifecourse of athletes, or athlete pathways, are constructed, supported and restricted by the social environment. They consider the complexity of athletes' pathways in relation to family, educations, sports systems and policy. Gijs van Campenhout and Joost Jansen examine some of the (inter)national controversies regarding foreign-born sportspeople, and how these numbers challenge notions of citizenship and nationhood. They also demonstrate ways in which meeting formal eligibility criteria does not automatically translate into being fully accepted as a true member of the nation. In Rylee Dionigi's chapter, she examines the perspectives and experiences of older people competing in sport and discusses how the findings from her extensive research in this area are both fascinating and revealing at the individual and societal levels.

The sixth part of the Handbook considers a number of social issues. The first three chapters consider issues for specific sporting populations. Lombe Mwambwa and Elizabeth Pike reflect on their ongoing research into women and sport, and mutual learning from their positions as a Black woman located in the Global South and a white woman located in the Global North. They draw on what they call an epistemology of the along, inviting the reader to consider that nothing is finished and the need to keep raising questions and consider possibilities. Anima Adjepong's chapter makes a case for directing increased scholarly attention to African women's sport in order to open up new avenues for scholarly engagement with social movements that seek equality for women and gender expansive Africans. Adjepong argues that a queer African studies approach to examining women's sport in Africa can undermine the weight of heterosexual patriarchy in sports and help imagine and realise more just societies. In Florian Kiuppis's chapter, the reader is introduced to the sport of Baskin as a best practice model of disability inclusive sport for all, by way of providing a discussion on disability in sport and society informed by his considerable work in this field.

The remaining chapters in this part explore issues that broadly relate to ethics and the well-being of those participating in sport. The issue of fairness and the integrity of sport is then examined by James Connor, who specifically focuses on doping. Connor considers the possibility that we still do not know the prevalence and consequently the gravity of the issue, and the likelihood of the further erosion of athlete rights as technologies of surveillance become ever more intrusive. Ivan Waddington provides an overview of the current state of knowledge in the sociology of pain and injury, drawing on his long research career in this field. He suggests a need for more theoretically driven research and closer alignment with 
the cognate subdiscipline of medical sociology. The reader is then introduced to the different forms of non-accidental violence in sport by Kari Fasting, including psychological, sexual, physical and neglect. Fasting overviews considerations related to prevention and safeguarding and demonstrates how the first studies had an impact on policy development. In Michael Atkinson's chapter, he examines sport's complicated relationship with mental health and illness, drawing on deeply personal experiences. Atkinson's research cautions against the privileging of potentially overused means of addressing areas of focus including depression, anxiety, suicide ideation and addiction. Ramón Spaaij then examines how violence, terrorism and the prevention of violent extremism have been taken up in sports research, policy and practice. He concludes by charting the knowledge translation practices and approach to impact that have characterised this research journey, with the aim to raise awareness among scholars about how their research can have impact beyond academia.

In the seventh part of the Handbook the final chapter is authored by a pre-eminent scholar in the sociology of sport. Jay Coakley provides a summary of his approach to sports and society over the last half-century and his strategy of combining scholarly work with teaching and service. Coakley suggests that it is important for sociology of sport associations and their scholar-members to embrace Burawoy's notion of public sociology if the sociology of sport is to remain a recognised topic of study. He gives particular consideration to the context of higher education and the budget reductions associated with the coronavirus pandemic. Coakley argues that the opportunities to do this are many as sports are impacted by the pandemic and the global protests against police brutality and racial injustice.

I would like to take this opportunity to express my gratitude to all the contributors to this Handbook whose lives were impacted by the global pandemic, and for many of whom the Black Lives Matter movement was deeply personal as well as political. Each of them remained committed to this project despite often incredibly challenging circumstances. I am inspired by their contributions both to this Handbook and to the wider debates regarding how research and scholarship might inform activism, and how sports might contribute to a future world of more just and humane societies.

\section{REFERENCES}

Bangsbo, J., Blackwell, J., Boraxbekk, C-J. et al. (2019), Copenhagen Consensus Statement 2019: Physical Activity and Ageing, British Journal of Sports Medicine, 53, 856-8.

Coakley, J. and Pike, E. (2014), Sports in Society: Issues and Controversies, London: McGraw Hill.

Donnelly, P., Darnell, S. and Kidd, B. (with Priyansh, Marc Lizoain and Mathew Blundell) (2020), Discussion Paper: The Implications of COVID-19 for Community Sport and Sport for Development, Toronto: Centre for Sport Policy Studies (Faculty of Kinesiology and Physical Education, University of Toronto).

Evans, A.B., Blackwell, J., Dolan, P. et al. (2020), Sport in the Face of the COVID-19 Pandemic: Towards an Agenda for Research in the Sociology of Sport, European Journal for Sport and Society, https://doi.org/10.1080/16138171.2020.1765100.

Piggott, L. and Pike, E. (2019) 'CEO Equals Man': Gender and Informal Organisational Practices in English Sport Governance, International Review for the Sociology of Sport, https://doi.org/10.1177/ 1012690219865980.

Pike, E. (2000). Illness, Injury and Sporting Identity, unpublished doctoral thesis. Loughborough University. 
Pike, E. (2014), Methodological Issues in Researching Physical Activity in Later Life, in Andy Smith and Ivan Waddington (eds), Doing Real World Research in Sport Studies, London: Routledge, pp. 131-40.

Pike, E. (2019), Aging, Sports and Society, in Joseph Maguire, Katie Liston, and Mark Falcous (eds), The Business and Culture of Sports, Farmington Hills, MI: Macmillan, pp. 231-51.

Pike, E., White, A., Matthews, J., Southon, S., and Piggott, L. (2018), Women and Sport Leadership: A Case Study of a Development Programme, in Jayne Caudwell, Louise Mansfield, Beccy Watson, and Belinda Wheaton (eds), The Palgrave Handbook of Feminisms in Sport, Leisure and Physical Education, Basingstoke: Palgrave Macmillan, pp. 809-23. 